\title{
Investigation and Countermeasures Analysis on Innovation and Entrepreneurship Education in Agricultural and Forestry Universities of Western China
}

\author{
--Taking $\mathbf{N}$ University of Sichuan as an Example \\ Jun Leng ${ }^{1}$, Xiaotong You ${ }^{2}$ \\ ${ }^{1}$ Student Affairs Office of Sichuan Agricultural University, Chengdu, Sichuan Province, China \\ ${ }^{2}$ College of Animal Science and Technology, Sichuan Agricultural University, Chengdu, Sichuan Province, \\ China
}

Keywords: college students, innovation and entrepreneurship education, investigation, countermeasures.

\begin{abstract}
Innovation and entrepreneurship education in colleges and universities is an important part in the national strategy of building an innovation-oriented country. In this paper, investigation is carried out from the perspectives of students' understanding and participation, the effectiveness of education, difficulties in students' participation. Countermeasures and suggestions are put forward accordingly.
\end{abstract}

\section{Introduction}

Innovative and entrepreneurial education is a new educational idea emerging with the advent of knowledge economy era. It originates in the United States, and then spreads to the world [1]. Carrying out innovation and entrepreneurship education in colleges and universities is the need for achieving higher education reform, the demand for realizing the full growth and employment of college students, and the requirement of implementing the strategy of building an innovation-oriented country. Promoting innovation and entrepreneurship education in colleges and universities is a historical necessity, and has very important practical significance [2]. For a long time, the traditional education in China focuses on the imparting of knowledge, but ignores the cultivation of ability, especially the cultivation of innovative consciousness and ability [3]. The traditional mode cannot meet today's actual needs. Agricultural and forestry universities are the important base of cultivating talents for agricultural industry. Innovation and entrepreneurship training plays an important role in achieving the comprehensive well-off society and the revitalization of rural areas. This study takes Sichuan $\mathrm{N}$ University as an example, and carries out investigation on the innovation and entrepreneurship education in agricultural and forestry universities. Analysis on investigation results and countermeasures are provided accordingly.

\section{Investigation organized}

In this study, network questionnaire is used. 441 students are randomly selected from various majors and grades, including 237 male students and 204 female students. 312 are undergraduates, including 99 freshmen, 81 sophomores, 63 juniors 69 seniors. 111 are graduates, including 36, 42 and 33 students from grade one, two and three. 18 are doctoral students. There are 25 questions grouped into 5 aspects in the survey. Questions include students' understanding on innovation and entrepreneurship education carried out by school, their willingness to participate, achievements of their participation, difficulties in participation and suggestions. 


\section{Investigation results}

Students' understanding on innovative and entrepreneurial education activities in school. 85.03\% students "have heard about innovative and entrepreneurial activities". The ratios of male and female students are $82.28 \%$ and $88.24 \%$ respectively. For undergraduates and graduates, the ratio increases with their grade grows. $63.64 \%$ freshmen have heard these activities, while the number rises to $95.65 \%$ in senior students. The average rate of graduate students is $91.81 \%$, which is higher than that of undergraduate students, $83.74 \%$, by eight points. $100 \%$ doctoral students have heard these activities. $68.71 \%$ respondents hold positive attitude on "the school authority carries out innovative and entrepreneurial education activities". $75 \%$ female students hold positive attitude, which is $11.71 \%$ higher than that of male students. For undergraduates, the ratio increases with their grade grows. $45.45 \%$ freshmen hold positive attitude, while the number rises to $73.91 \%$ in senior students. The ratios of graduate students from three grades are similar; the average ratio is $75.43 \%$. The rate of doctoral students is $83.33 \%$.

Students' willingness to participate in innovative and entrepreneurial activities. 82.99\% respondents express that they are "willing to participate". The proportions of master and doctoral students are both $100 \%$. The ratios of undergraduates at all grades are normal distribution. The ratios are $69.7 \%, 81.48 \%, 85.71 \%$ and $69.57 \%$ respectively. The number of people who "want to take part in entrepreneurial projects" is relatively small; the ratio is only $57.82 \%$. The proportion of undergraduates is $66.25 \%$, and the ratios at all grades are normal distribution. The ratio of master student is $43.07 \%$, and it decreases with the increase of grades. The proportion of doctoral students is only 33.33\%. 62.59\% students want to "participate in innovative and entrepreneurial competitions". The number sharply decreases with the increase of grades. The ratios of undergraduate students, graduate students and doctoral students are 69.12\% 44.95\% and 16.67\%. 83.67\% respondents "want to publish papers", and the proportions of master and doctoral students are $100 \%$. The proportions of undergraduate students at four grades are $72.73 \%, 92.59 \%, 85.71 \%$ and $56.52 \%$ respectively with normal distribution. The proportion of girls is significantly higher than that of boys, and the proportions are $74.68 \%$ and $94.12 \%$ respectively. The proportions of students who "want to do research in the future" and "want to start up business in the future" are not very high. The proportion of the former is significantly higher than the latter, and the proportions are $44.22 \%$ and $21.09 \%$ respectively. The willingness of undergraduate and postgraduate students to do research grows with the increase of grades. The proportion of Ph.D. students reaches $83.33 \%$. The proportions of students who have entrepreneurial intentions at all grades are basically the same, and decrease slightly with the increase of grade.

The situation of students' participation in innovative and entrepreneurial activities. The proportion of students who "are participating or have participated in research projects" is $57.14 \%$. The proportion of female students, $67.65 \%$, is significantly higher than that of male students, $48.10 \%$. The ratios of master and doctoral students are both $100 \%$. The proportions of undergraduate students grow with the grade increasing, ranging from $6.06 \%, 40.74 \%, 61.90 \%$ to $65.22 \%$. The proportion of students who "are participating or have participated in entrepreneurial projects"'" is just $16.55 \%$. The ratios of undergraduate and postgraduate students' participation rise along with the increasing grade. The ratios of freshmen, sophomores, juniors and seniors are 1.01\%, 12.35\%, $17.46 \%$ and $21.74 \%$. The ratios of master students from grade one to three are $22.22 \%, 28.57 \%$ and $30.30 \%$. The ratio of doctoral students is $33.33 \%$. The proportion of students who "are participating or have participated in innovative and entrepreneurial competitions" is $33.33 \%$. The ratios of undergraduate and postgraduate students' participation rise along with grade increasing. The ratios of freshmen, sophomores, juniors and seniors are $3.03 \%, 27.16 \%, 44.44 \%$ and $46.38 \%$. The ratios of master students from grade one to three are $41.67 \%, 45.24 \%$ and $54.55 \%$. The ratio of doctoral students is $55.56 \%$.

Students' achievements in innovative and entrepreneurial activities. 26.3\% respondents "have won at least one prize above or equal to college level". The ratios of undergraduate and postgraduate students' participation rise along with grade increasing. The proportion of doctors is the highest, 
reaching $50 \%$. The ratios of freshmen, sophomores, juniors and seniors are $0,18.52 \%, 31.75 \%$ and $37.68 \%$. The ratios of master students from grade to three are $38.89 \%, 40.48 \%$ and $45.45 \%$. $29.25 \%$ students "have published papers". The proportions of female and male are $34.8 \%$ and $24.8 \%$. 100\% doctoral students have published papers. The ratios of undergraduate and postgraduate students' participation rise along with grade increasing. The ratios of freshmen, sophomores, juniors and seniors are $1.01 \%, 11.11 \%, 25.4 \%$ and $31.88 \%$. The ratios of master students from grade one to three are $33.33 \%, 57.14 \%$ and $81.82 \%$. Only $16.33 \%$ of all respondents "have published collected papers". The proportion of female students is $20.59 \%$, higher than male students by 8 points. The ratio of doctoral students is $100 \%$. For freshmen and sophomores, the number is 0 . The ratios of juniors and seniors are $4.76 \%$ and $8.70 \%$. The ratios of master students from grade one to three are $25 \%, 35.71 \%$ and $63.64 \%$.

Difficulties and suggestions on students' participation in innovative and entrepreneurial activities. Arranging from their influence on participation, the difficulties are: lack of personal abilities (87.76\%), not familiar with relevant policies (64.63\%), lack of cooperation team (60.54\%), lack of willingness (57.82\%), lack of guidance (50.57\%) and lack of resources and platform (49.66\%). Above $80 \%$ of students from all grades choose ability deficiency. The proportion decreases slightly with the growth of grade. The proportion of "lack of willingness" increases with the grade, while other items decrease. Over 90\% students suggest the school "to strengthen the knowledge imparting and skills training" and "strengthen team integration"; the ratios are 92.52\% and 91.84\% respectively. The proportions of other suggestions are as follows: to strengthen policy interpretation accounts for 70.75\%; enrich innovative and entrepreneurial platforms accounts for 61.22\%; strengthening guidance accounts for 59.18\%. The proportions of five suggestions decrease with the growth of grades among undergraduate and graduate students. No doctoral students choose "strengthen policy interpretation", "enrich innovative and entrepreneurial platforms" or "strengthening guidance".

\section{Results analysis}

Analyzing from students' understanding and the degree of recognition. Students' high awareness of innovation and entrepreneurship activities is closely related to the implementation of the national strategy of "public entrepreneurship and innovation" and the publicity of schools as well as all levels of government. The lower awareness rate is about $17 \%$, indicating the existing mode cannot meet students' expectations due to single content, lack of pertinence and low level repetition. The rate of recognition increases with the growth of grade, which is closely related to the gradual understanding and deep participation, and leaves great space for schools. High grade students, especially doctoral students have high recognition rates, showing that the overall positioning, as well as the working ideas and practices of school authority are basically reasonable.

Analyzing from students' willingness to participate in innovative and entrepreneurship activities. The willingness of students to participate in scientific research is $25 \%$ and $20 \%$ higher than that of participating in entrepreneurial projects as well as innovation and entrepreneurship competitions, which is related to the strong academic atmosphere of universities. Compared with the academic research, entrepreneurship and management competition requires students to balance their research, study and free time. On that basis, participants also need to put more efforts on innovation, teamwork, policy interpretation, resource integration, psychological quality and other aspects, which affect their willingness to participate. Academic paper can measure the learning outcomes and innovative abilities of students, and is the passport to graduation and employment. Therefore, 83\% respondents want to publish papers. The proportion of female students is significantly higher than that of male students, since females are more willing to participate in scientific research. Students participate in innovative and entrepreneurial activities to exercise abilities; but most students engage in scientific research and entrepreneurship as their lifelong career. These options make high demands on the comprehensive qualities and resources of students. Students tend to choose them prudently, and the proportions are relatively low.

Analyzing from students' participation in innovative and entrepreneurial activities. Nearly $60 \%$ of students express, they "are participating or have participated in scientific research projects". It is 
related to school authority's attention and the increasing input in scientific research. The proportion of masters and doctors are $100 \%$, which is closely related to the training target. The proportion of girls is significantly higher than that of boys, which is in line with the basic rule that females are more willing to participate in scientific research. The proportion of undergraduate students increases with the growth of grade, indicating that the opportunity to participation increases with the time they spent in campus.

The proportion of students who "are participating or have participated in entrepreneurial projects" is about $20 \%$ less than students' participation in scientific research, which is basically consistent with the analysis of willingness. The ratios of undergraduate students from different grades are normal distribution. A possible reason is that, low grade students have fewer opportunities, while high grade students are not willing to participate due to pressures for employment and further study. For master students, the rate decreases with the increasing of grade, while the proportion of doctoral students is the lowest. The trend is the opposite with students' participation in research projects, and is in line with the students' participation in entrepreneurial projects. This reflects that school authority needs to put more efforts on the transformation and balance between entrepreneurship and academic research. For undergraduate and graduate students, the proportion of students who "are participating or have participated in innovative and entrepreneurship competitions" grows with the grade increasing. The proportion of $\mathrm{PhD}$ students is the highest; it is positively correlated with the time they spent in school.

Analyzing from students' achievements of participating in innovative and entrepreneurship activities. The ratios of students who "have won at least one prize above or equal to college level" and "have published papers" rise along with grade increasing. The proportions of doctors are the highest. Senior students have spent long time in school, and they are access to more platforms, guidance and resources; their capabilities are also improved during the school years. The trend is in line with the rule of college students' growth. Collected papers reflect high level research achievements. The proportion of doctoral students who "have published collected papers" is much higher than that of master students and undergraduates, indicating that research achievements are closely related to academic resources, views, as well as accumulation and cultivation orientation.

Analyzing from difficulties and suggestions of students' participation in innovative and entrepreneurship activities. The difficulty with highest proportion is "lack of personal abilities". Above $80 \%$ of students from all grades choose this item, indicating that students are cautious in self-assessment, and think highly of their own capacity. The ratio slightly decreases with the increasing grade, which is in line with college education and student growth rules. Different from other items, the proportion of "lack of willingness" grows with the increasing grade at all levels, indicating that students are able to adapt to the diversification of personnel training and evaluation system; their options are also diversified.

Most students hold that, main difficulties in participating innovative and entrepreneurship activities are objective factors include not familiar with relevant policies, lack of cooperation team, lack of willingness, lack of guidance resources and lack of platforms. Many students suggest the school to strengthen knowledge imparting and skills training, strengthen team integration and policy interpretation, and enrich platforms for innovative and entrepreneurial activities. All these ratios decrease with the growth of grade, which is in line with the rule of university education, and points out the development direction and focus of university innovation and entrepreneurship education.

\section{Countermeasures and Suggestions for the Development of Innovative and Entrepreneurial Education in Colleges and Universities}

\subsection{Looking forward, strengthening publicity and creating education atmosphere}

"Mass entrepreneurship and innovation" is an important way to realize an innovative-oriented country. Universities should take up responsibility actively, and incorporate innovation and entrepreneurship education into planning. The "forward-looking" positioning is the foundation for innovation and entrepreneurship education. Colleges and universities should attach great importance to it, regard it as the urgent need to promote personnel training, higher education reform and 
connotative development, and take it as an effective way to cultivate the employment abilities of college students. Innovation and entrepreneurship education can cultivate students' innovative thinking methods, strengthen their entrepreneurial abilities, and improve their competitiveness. Colleges and universities should popularize the knowledge and skills of innovation and entrepreneurship education, and strengthen the publicity in the whole society with departments at all levels. Thus, teachers and students will be able to better understand innovation and entrepreneurship education, and actively participate in it; meanwhile, good social atmosphere will also be created to attract the attention and participation from the whole society.

\subsection{Strengthening the construction of comprehensive innovation and entrepreneurship education system}

To carry out innovation and entrepreneurship education, it is necessary to strengthen the construction of a comprehensive educational system including teachers, courses and assessment. Firstly, a group of open minded teachers with high professional skills is the key to the success of innovation and entrepreneurship education. The school authority should do everything possible to improve teachers' professional levels. Teachers' innovative consciousness, abilities and experiences can be improved and enriched through targeted selection and training. Enterprises employees should also be encouraged to participate in the project as part-time teachers. By the combination of full-time and part-time teachers, the school authority can fully integrate social resources. Experts and entrepreneurs with innovation and entrepreneurial experience can also be invited as tutors to improve the overall level of teachers.

Secondly, perfect curriculum is an important part in the implementation of innovation and entrepreneurship education. It is necessary to establish a scientific and reasonable curriculum system with characteristics of innovative and entrepreneurship education [4]. Innovation and entrepreneurship related courses should be included in public basic courses; knowledge on economic, management and law should be covered in these courses. The innovation and entrepreneurship education should integrate theory with practice, combine compulsory teaching with optional courses, and achieve the organic interaction between first and second classes.

Thirdly, the scientific evaluation system is the key to innovation and entrepreneurship education. Colleges and universities must follow the rules of innovation, and establish a scientific and rational assessment system which encourage innovative and entrepreneurial attempts, and can be inclusive to their failures. Monitoring, evaluation and tracking system on teaching quality should also be built to realize the effective supervision and evaluation of teaching process and teaching effects, and to further improve the development of innovation and entrepreneurship education. The school should try to protect and mobilize the enthusiasm of teachers and students, and abandon traditional appraisal method and the eager to quick success; diversified measures should be taken to make the evaluation system more scientific.

\subsection{Exploring the management of whole process and following up service}

Students are the main body of innovation and entrepreneurship; they need to be linked with procedures of policy interpretation, project docking, guidance and platform providing, as well as project incubation and conversion. The management and following up service is necessary for the improvement of education quality and the enhancement of success rate. The school should give full play of its role as the bridge, follow the "person-position fit" idea, and organize policy interpretation lectures, innovation and entrepreneurship competitions, as well as mutual selection meetings to improve the participation rate and accuracy. Training and incubation bases should be established and equipped with necessary venues, facilities and equipment; relevant services such as consultations on law, industry, commerce, taxation, finance and management, as well as services on personnel agency, project recommendation and financing should also be provided to promote the innovation and entrepreneurship of college students. For projects embodied with science and technology contents, and projects which have market prospects and development space, customized services about policy guidance, technical support and resource docking should be offered. In addition, universities should also strengthen the follow-up transformation of projects and carry out targeted investigations, in order 
to better promote innovation and entrepreneurship education, management and service in universities.

\section{Acknowledgement}

Fund Project: This paper is one of the outcomes of the research, Developing New Working Patterns on Students Affairs to Adapt to the Construction of World-class Universities and First-class Disciplines, which is supported by the Foundation for Key Research Projects on Innovations in Instructors' Work in Sichuan Agricultural University.

\section{References}

[1] X.J. Gao, S.L. Cao, Innovation and entrepreneurship education: cultivating pioneers of the new era, J. Chinese Higher Education Research. 7 (2007).

[2] H.B. Li, Policy recommendations for promoting innovation and entrepreneurship education in colleges and universities, J. Bulletin of Science and Technology. 4 (2014).

[3] J.Q. Li, Analysis of the present situation of higher education in China and countermeasures analysis: from the perspective of all-round development of human beings, J. Journal of Shanghai Jiaotong University. 2 (2003).

[4] Y.F. Guan, H. Gao, the present situation and countermeasures of promoting innovative and entrepreneurial education in colleges and universities, J. Journal of Jiangsu Radio \& Television University. 6 (2011). 